\title{
Derivation of age-adjusted LACE index thresholds in the prediction of mortality and frequent hospital readmissions in adults
}

\author{
Christopher Henry Fry ${ }^{1}$ Erica Heppleston ${ }^{2}$. David Fluck ${ }^{3}$. Thang Sieu Han ${ }^{4,5}$
}

Received: 27 April 2020 / Accepted: 10 July 2020 / Published online: 28 July 2020

(c) The Author(s) 2020

\begin{abstract}
The LACE index has been shown to predict hospital readmissions and death with variable accuracy. A LACE index $\geq 10$ is considered as high risk in the existing literature. We aimed to derive age-specific LACE index thresholds in the prediction of mortality and frequent readmissions. Analysis of prospectively collected data of consecutive alive-discharge episodes between 01/04/2017 and 31/03/2019 to a single hospital was conducted. The derivation of LACE index thresholds for predicting all-cause mortality within 6 months of hospital discharge or frequent readmissions ( $\geq 2$ times within 28 days) was examined by receiver operating characteristics (ROC) in 32270 patients (14878 men, 17392 women) aged 18-107 year (mean $=64.0$ years, $\mathrm{SD}=20.5$ ). For all patients with a LACE index $\geq 10$, the area under the curve (AUC) for predicting mortality was $80.5 \%$ (95\% CI 79.7-81.3) and for frequent readmissions was 84.0\% (83.0-85.1). Two-graph ROC plots showed that the LACE index threshold where sensitivity equates specificity was 9.5 (95\% intermediate range $=5.6-13.5)$ for predicting mortality and $10.3(95 \%$ intermediate range $=6.6-13.6)$ for frequent readmissions. These thresholds were lowest among youngest individuals and rose progressively with age for mortality prediction: $18-49$ years $=5.0,50-59$ years $=6.5$, $60-69$ years $=8.0,70-79$ years $=9.8$ and $\geq 80$ years $=11.6$, and similarly for frequent readmissions: $18-49$ years $=5.1,50-59$ years $=7.5,60-69$ years $=9.1,70-79$ years $=10.6$ and $\geq 80$ years $=12.0$. Positive and negative likelihood ratios (LRs) ranged 1.5-3.3 and 0.4-0.6 for predicting mortality, and 2.5-4.4 and 0.3-0.6 for frequent readmissions, respectively, with stronger evidence in younger than in older individuals (LRs further from unity). In conclusion, the LACE index predicts mortality and frequent readmissions at lower thresholds and stronger in younger than in older individuals. Age should be taken into account when using the LACE index for identifying patients at high risk.
\end{abstract}

Keywords Emergency medicine $\cdot$ Health economics $\cdot$ Public health $\cdot$ Likelihood ratio $\cdot$ ROC analysis

Electronic supplementary material The online version of this article (https://doi.org/10.1007/s11739-020-02448-3) contains supplementary material, which is available to authorized users.

Thang Sieu Han

thang.han@rhul.ac.uk

1 School of Physiology, Pharmacology and Neuroscience, University of Bristol, Bristol BS8 1TD, UK

2 Quality Department, Ashford and St Peter's NHS Foundation Trust, Guildford Road, Chertsey, Surrey KT16 0PZ, UK

3 Department of Cardiology, Ashford and St Peter's NHS Foundation Trust, Guildford Road, Chertsey, Surrey KT16 0PZ, UK

4 Department of Endocrinology, Ashford and St Peter's NHS Foundation Trust, Guildford Road, Chertsey, Surrey KT16 0PZ, UK

5 Institute of Cardiovascular Research, Royal Holloway, University of London, Egham, Surrey TW20 0EX, UK

\author{
Abbreviations \\ AUC Area under the curve \\ ICD International classification of diseases \\ IR Intermediate range \\ LACE Length of stay, acuity of admission, comorbidity \\ and emergency department visits \\ LR Likelihood ratio \\ NHS National Health Service \\ ROC Receiver operating characteristic
}

\section{Introduction}

The number of emergency admissions to National Health Service (NHS) hospitals reached 6.6 million between December 2018 and November 2019 [1]. A recent report revealed that $13.8 \%$ of patients were readmitted within 30 days of hospital discharge during 2017-2018, rising from 
$12.5 \%$ in 2013-2014 [2]. Frequent readmissions are more costly than index admissions [3] and consume a large proportion of healthcare resources [4]. About $15-20 \%$ of readmissions are potentially avoidable [5] and reducing hospital readmissions has, therefore, been prioritised by healthcare services $[6,7]$. Therefore, the ability to identify patients who are at risk of frequent readmissions would provide crucial information for effective healthcare service planning $[8,9]$. The LACE index scoring algorithm provides such a tool [10], and has been implemented worldwide, including in the UK [11-13].

The LACE index score is based on Length of stay, Acuity of admission, Comorbidity and Emergency department visits, with a scale ranging from 0 to 19 [10]. The threshold at 10 of this index has been commonly used to indicate an increased likelihood of outcome risks, such as frequent readmissions and mortality [14-17]. However, the test accuracy of the LACE index for predicting readmissions and mortality has variably been reported [11-15]. Because advancing age is the ultimate determinant of mortality, the readmission frequency among older individuals diminish with years of follow up [18]. Thus, LACE index thresholds associated with a high risk of mortality and readmissions may vary with age. In this study, we examined the age-specific performance of the LACE index and derived LACE index thresholds to identify adults at increased risk of all-cause unplanned frequent readmissions and mortality after a hospital discharge.

\section{Methods}

\section{Study design, participants and setting}

We analysed prospectively collected data of consecutive alive-discharge episodes of unplanned admissions over two financial years between 1st April 2017 and 31st March 2019 to a single NHS. The data comprised clinical characteristics and care quality, including the length of stay and number of previous emergency department visits [19]. In line with the NHS data collection for general hospital admissions, cancer and obstetrics cases were excluded [2].

\section{Measurement}

Morbidities were coded according to the international classification of diseases (ICD-10) for calculation of the Charlson co-morbidity index [20, 21]. Information on all-cause unplanned admissions and frequency of readmissions within 28 days, and all-cause mortality within 6 months and within 30 days of discharge from hospital was documented. The LACE index was computed from the length of stay (score range $0-7$ ), acuity of admission (score 0 or 3), comorbidity (score range 0-5) and emergency department visits (score range 0 or 4) [22] - these scores summated to a scale of between 0 and 19 [10].

\section{Categorisation of variables}

Frequent readmissions were defined as those who were readmitted two or more times within 28 days from an index discharge from hospital. Age was categorised by decades from 50 to 79 years: $50-59,60-69,70-79$ and $\geq 80$ years. All patients between 18 and 49 years were combined for the youngest age category due to lower mortality rates, and all those $\geq 80$ years were also combined for the oldest category due to relatively small numbers of patients over 90 years.

\section{Statistical analysis}

Receiver operating characteristic (ROC) curves were constructed to determine the area under the curve (AUC) for the LACE index as a predictor of outcomes (mortality or frequent admissions). Positive (LR+) and negative (LR-) likelihood ratios were calculated as $\frac{\text { sensitivity }}{1-\text { specificity }}$ and $\frac{1-\text { sensitivity }}{\text { specificity }}$, respectively. Two-graph ROC curve analysis was conducted to optimise the selection of the maximum test accuracy for a given LACE index threshold value for identifying at-risk individuals, by plotting an overlapping graph of sensitivity and specificity curves as a function of the LACE index scores. The threshold $d_{0}$ was obtained by interpolating from the intersection where sensitivity equals specificity $\left(\theta_{0}\right)$, and the intermediate range $\left(\mathrm{IR}_{95 \%}\right)$ was determined by the distance between the two points where sensitivity (lower limit) and specificity (upper limit) equal 95\% [23-25]. ROC analysis was performed first for all patients and then for different age bands to obtain age-specific results. Analyses were performed using IBM SPSS Statistics, v23.0 (IBM Corp., Armonk, NY).

\section{Results}

Data for a total of 32,270 patients $(14,878$ men $)$ and $(17,392$ women $)$ aged $18-107$ years $($ mean $=64.0$ years, $\mathrm{SD}=20.5$ ) were analysed. There were $29.3 \%$ of patients with a LACE index score of $\geq 10$ : $6.8 \%$ of patients died within 6 months (mean age of death $=81.2$ years, $S D=12.1$ ); $2.6 \%$ died within 30 days of hospital discharge (mean age of death $=81.5$ years, $\mathrm{SD}=12.0$ ) and $3.3 \%$ of patients were readmitted $\geq 2$ times within 28 days of hospital discharge. Among those aged $18-49$ years $(n=8403), 50-59$ years ( $n=4304), 60-69$ years $(n=4739), 70-79$ years $(n=6068)$ and $\geq 80$ years $(n=8756)$ respectively, the rates of mortality within six months of discharge were $0.5 \%, 2.0 \%, 4.8 \%$, $7.7 \%$ and $15.6 \%$, and within 30 days of discharge were $0.2 \%$, 
$0.7 \%, 1.8 \%, 2.9 \%$ and $6.0 \%$; frequent readmissions within 28 days of discharge were $1.0 \%, 1.5 \%, 2.4 \%, 3.3 \%$ and $6.7 \%$. For clarity of presentation, only data for mortality within six months of discharge and readmissions within 28 days of discharge from hospital are presented subsequently. The results for mortality within 30 days of discharge, which closely follow the results of mortality within 6 months of discharge, are available in Supplementary material.

ROC analysis to generate AUC values for all patients (18-107 years) showed that the LACE index as a predictor of mortality within 6 months of hospital discharge was 80.5\% (95\% CI 79.7-81.3) (Fig. 1a) and frequent readmissions were $84.0 \%$, (95\% CI 83.0-85.1) (Fig. 1b). Age-specific analysis of mortality showed that the AUC was highest among youngest individuals and diminished progressively with age: $18-49$ years $=79.6 \%, 50-59$ years $=78.1 \%$, $60-69$ years $=71.4 \%, \quad 70-79$ years $=72.0 \%$ and $\geq 80$ years $=63.9 \%$ (Table 1 ). By contrast, analysis of frequent readmissions showed that AUCs $(>80 \%)$ were similarly high across different age groups, except for the oldest group where the value dropped to $76 \%$ (Table 1). Similar results were observed for the prediction of mortality within 30 days of hospital discharge (Supplementary Table 1).

Table 2 shows that within each of the five age categories (18-49 years, 50-59 years, 60-69 years, 70-79 years and 80 years), the $\mathrm{LR}+$ values were $3.34,2.53,2.09,1.96$ and 1.53 , and LR- values were $0.40,0.39,0.41,0.45$ and 0.63 for age-specific LACE thresholds for predicting the probability of mortality within 6 months of hospital discharge. The corresponding $\mathrm{LR}+$ values were $3.30,3.60,4.38,3.32$ and 2.51, and LR- values were $0.42,0.28,0.32,0.26$ and 0.59 for predicting frequent readmissions within 28 days of discharge from hospital.

For all patients, two-graph ROC plots showed the LACE index threshold where sensitivity equals specificity for predicting mortality within 6 months was 9.5 $\left(\mathrm{IR}_{95 \%}=5.6-13.5\right)$ (Fig. 2a) and frequent readmissions were $10.3\left(\mathrm{IR}_{95 \%}=6.6-13.6\right)$ (Fig. 2b). The LACE index threshold for predicting mortality within 6 months was lowest among youngest individuals and rose progressively with age: $18-49$ years $=5.0,50-59$ years $=6.5,60-69$ years $=8.0$, $70-79$ years $=9.8$ and $\geq 80$ years $=11.6$, and similarly for frequent readmissions: $18-49$ years $=5.1,50-59$ years $=7.5$, $60-69$ years $=9.1,70-79$ years $=10.6$ and $\geq 80$ years $=12.0$ (Table 3). Results from analysis of the LACE index in relation to mortality and frequent readmissions within 30 days of hospital discharge showed similar patterns (Supplementary Table 1).

Among the 44 patients in the youngest age group (18-49 years) who died within 6 months of hospital discharge, only eight patients (18.2\%) were identified using LACE index threshold at 10 compared with 35 patients (79.5\%) who were identified using the age-specific threshold

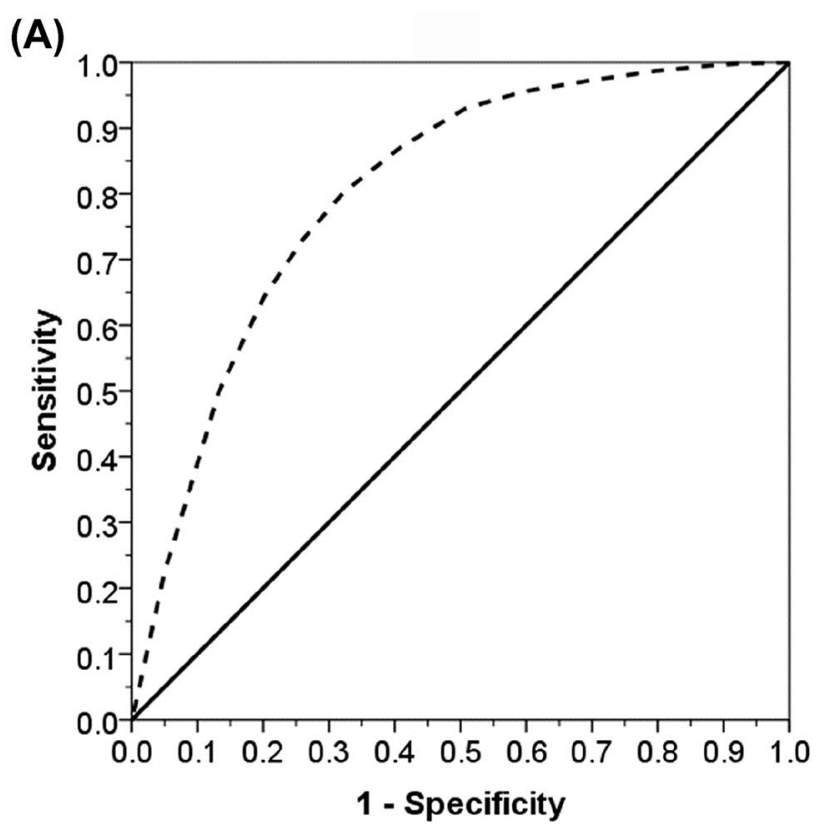

(B)

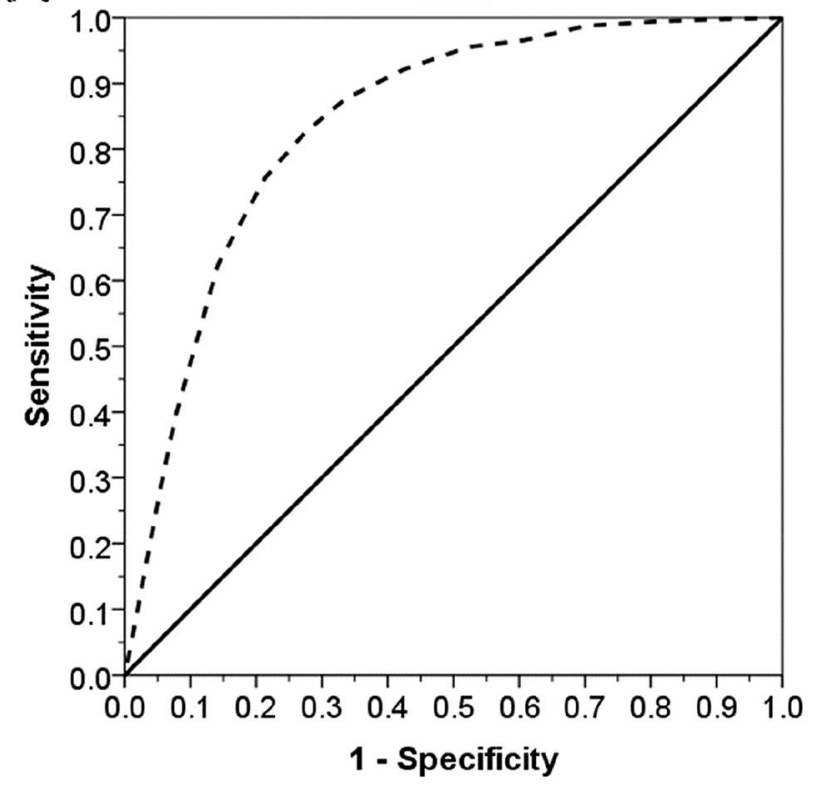

Fig. 1 ROC curves (dotted lines) to estimate the ability of LACE to predict: a all-cause mortality within 6 months of discharge and $\mathbf{b}$ frequent admissions within 28 days of discharge from hospital, in adults aged $18-107$ years. The solid $45^{\circ}$ line $(\mathrm{AUC}=50 \%)$ reflects a random classifier between the LACE index and either clinical outcome

at 5 . However, the false-positive rate rose from $1.6 \%$ to $33.2 \%$ when the LACE threshold was lowered from 10 to 5 . Similarly, among 87 patients in the youngest age group with frequent readmissions within 28 days of hospital discharge, only $15(17.2 \%)$ individuals were identified using LACE index threshold at 10 compared with 75 (86.2\%) individuals who were identified using LACE index threshold at 5. 
Table 1 ROC analysis for allcause mortality within 6 months or 30 days of discharge, and frequent readmission within 28 days of discharge from hospital based on a LACE index score $\geq 10$

\begin{tabular}{|c|c|c|c|c|c|c|c|}
\hline & \multirow[t]{3}{*}{$n$} & \multicolumn{6}{|c|}{ Receiver operating characteristic analysis } \\
\hline & & \multicolumn{3}{|c|}{$\begin{array}{l}\text { Died within } 6 \text { months of hospital } \\
\text { discharge }\end{array}$} & \multicolumn{3}{|c|}{$\begin{array}{l}\text { Readmitted } \geq 2 \text { times within } \\
28 \text { days of hospital discharge }\end{array}$} \\
\hline & & AUC (\%) & $95 \%$ CI & $P^{*}$ & $\operatorname{AUC}(\%)$ & $95 \% \mathrm{CI}$ & $P^{*}$ \\
\hline All patients (18-107 years) & 32,270 & 80.5 & $79.7-81.3$ & $<0.001$ & 84.0 & $83.0-85.1$ & $<0.001$ \\
\hline \multicolumn{8}{|l|}{ Age bands } \\
\hline $18-49.9$ years & 8403 & 79.6 & $72.2-86.9$ & $<0.001$ & 83.0 & $78.8-87.2$ & $<0.001$ \\
\hline $50-59.9$ years & 4304 & 78.1 & $73.3-82.9$ & $<0.001$ & 85.5 & $81.9-89.1$ & $<0.001$ \\
\hline $60-69.9$ years & 4739 & 74.4 & $71.0-77.8$ & $<0.001$ & 86.2 & $83.4-88.9$ & $<0.001$ \\
\hline $70-79.9$ years & 6068 & 72.0 & $69.6-74.4$ & $<0.001$ & 83.7 & $81.6-85.8$ & $<0.001$ \\
\hline$\geq 80$ years & 8756 & 63.9 & $62.3-65.4$ & $<0.001$ & 76.0 & $74.4-77.6$ & $<0.001$ \\
\hline
\end{tabular}

$* P$ value significantly different form $\mathrm{AUC}=50 \%$
(A)

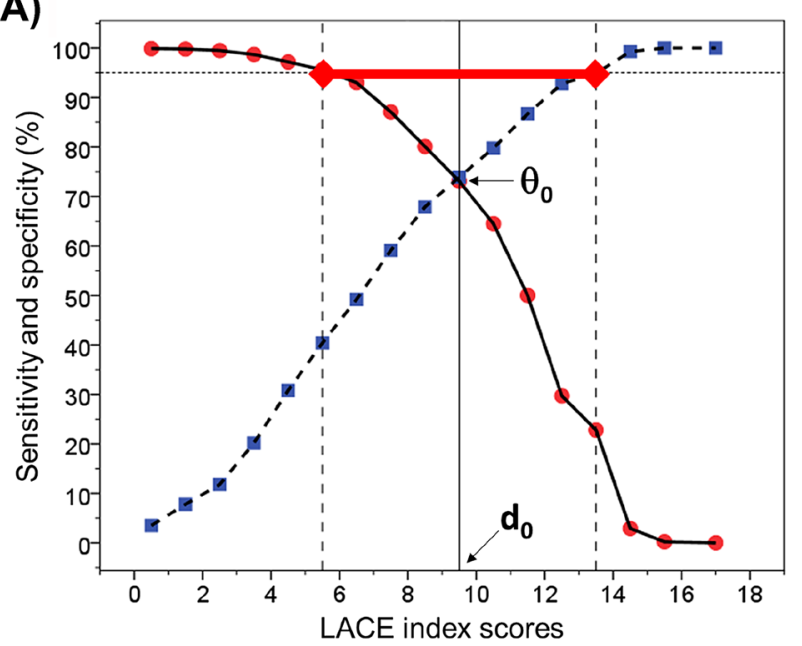

(B)

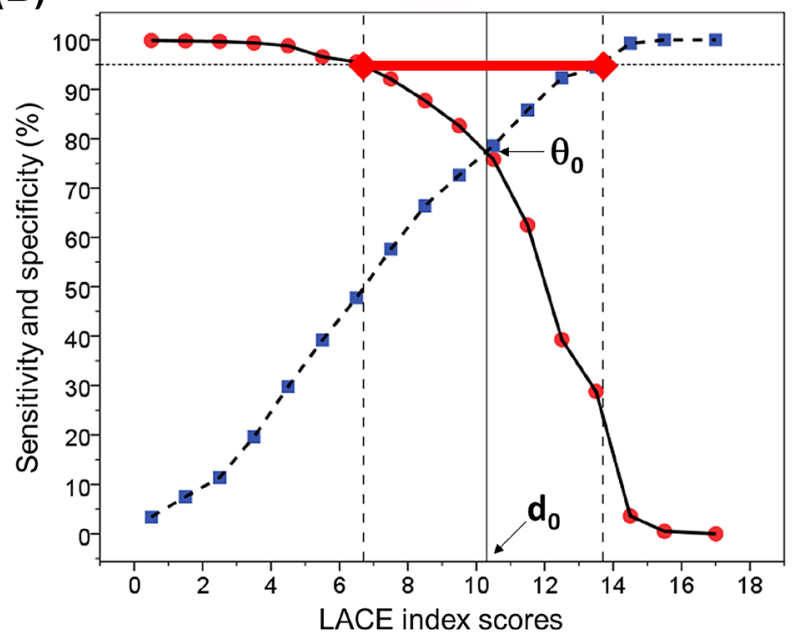

Fig. 2 Two-graph ROC plot to identify: a mortality within 6 months and $\mathbf{b}$ frequent admissions within 28 days of discharge from hospital. These show the threshold of the LACE index $\left(d_{0}\right)$ interpolated from the point where sensitivity (filled circle) equals specificity (filled square) $\left(\theta_{0}\right)$, and the intermediate range (red bar) where sensitivity $=95 \%$ (lower limit) and specificity $=95 \%$ (upper limit) in adults aged $18-107$ years
Table 2 Likelihood ratios for age-specific LACE thresholds to estimate the probability of mortality within 6 months of discharge and frequent readmissions within 28 days of discharge from hospital

\begin{tabular}{llllll}
\hline Age bands & $\begin{array}{l}\text { Died within 6 months of } \\
\text { hospital discharge }\end{array}$ & \multicolumn{2}{l}{$\begin{array}{l}\text { Readmitted } \geq 2 \\
\text { times within } \\
\text { 28 days of hospital } \\
\text { discharge }\end{array}$} \\
\cline { 2 - 3 } & LR+ & LR- & & LR+ & LR- \\
\hline 18-49 years & 3.34 & 0.40 & 3.30 & 0.42 \\
50-59 years & 2.53 & 0.39 & & 3.60 & 0.28 \\
60-69 years & 2.09 & 0.41 & & 4.38 & 0.32 \\
$70-79$ years & 1.96 & 0.45 & 3.32 & 0.26 \\
$\geq 80$ years & 1.53 & 0.63 & 2.51 & 0.59 \\
\hline
\end{tabular}

$L R+$ positive likelihood ratio; $L R-$ negative likelihood ratio

Table 3 LACE index thresholds where sensitivity equals specificity $\left(\theta_{0}\right)$ and $95 \%$ intermediate range derived from two-graph ROC plots

\begin{tabular}{|c|c|c|c|c|c|}
\hline & \multirow[t]{3}{*}{$n$} & \multicolumn{4}{|c|}{$\begin{array}{l}\text { LACE index threshold }\left(\theta_{0}\right) \text { and } \\
95 \% \text { intermediate range (IR) }\end{array}$} \\
\hline & & \multicolumn{2}{|c|}{$\begin{array}{l}\text { Died within } 6 \\
\text { months of hos- } \\
\text { pital discharge }\end{array}$} & \multicolumn{2}{|c|}{$\begin{array}{l}\text { Readmitted } \geq 2 \\
\text { times within } \\
28 \text { days of hos- } \\
\text { pital discharge }\end{array}$} \\
\hline & & $\theta_{0}$ & $95 \%$ IR & $\theta_{0}$ & $95 \%$ IR \\
\hline $\begin{array}{l}\text { All patients }(18- \\
107 \text { years })\end{array}$ & 32,270 & 9.5 & $5.6-13.5$ & 10.3 & $6.6-13.6$ \\
\hline \multicolumn{6}{|l|}{ Age bands } \\
\hline $18-49.9$ years & 8403 & 5.0 & $0.8-7.8$ & 5.1 & $3.0-7.7$ \\
\hline $50-59.9$ years & 4304 & 6.5 & $3.7-10.0$ & 7.5 & $5.1-9.8$ \\
\hline $60-69.9$ years & 4739 & 8.0 & $3.9-11.8$ & 9.1 & $6.7-11.8$ \\
\hline $70-79.9$ years & 6068 & 9.8 & $5.6-13.1$ & 10.6 & $8.1-13.2$ \\
\hline$\geq 80$ years & 8756 & 11.6 & $7.2-14.4$ & 12.0 & $10.3-14.4$ \\
\hline
\end{tabular}


The use of age-specific LACE index thresholds continues to identify more patients at risk of death or frequent readmissions up to the age of 69 years. There were fewer oldest patients ( $\geq 80$ years) being identified by an age-specific LACE index threshold of 11.5 (Supplementary Table 2). The patterns were similar for the relationship between agespecific LACE index thresholds and mortality with 30 days of hospital discharge.

\section{Discussion}

This study over a period of 2 years found that a high LACE index $(\geq 10)$ was associated significantly to all-cause mortality within 6 months of discharge and frequent admissions within 28 days of discharge from hospital. The thresholds of LACE index values where sensitivity equals specificity (maximum test accuracy) for identifying mortality and frequent admissions were lowest among younger individuals and rose progressively with age. As far as we are aware, this is the first study to demonstrate an age-specific association of the LACE index with mortality and frequent readmissions.

The results observed in this study show the test accuracies of the LACE index to predict mortality or frequent readmissions are relatively high compared $(>80 \%)$ with those in the published literature. Previous studies have reported a test accuracy of the LACE index to be between 55\% and $82 \%$ to predict readmissions [11-15], and between $66.3 \%$ and $83 \%$ to predict mortality after a hospital discharge [11, $13,15]$. These differences may be due to varying underlying conditions of the patients or their age range. We, therefore, extended our analysis further to assess an age-specific performance of the LACE index. It showed that the test accuracy was highest among the youngest age group and declined progressively with age in its ability to predict mortality. Moreover, test accuracy to predict frequent readmissions was generally high (AUCs $>83 \%$ ) up to 79 years, after which AUC dropped to $76 \%$ for the oldest group ( $\geq 80$ years). The poorer performance by the LACE index to predict readmissions among older individuals may be due to higher mortality rates among this age group. Although health insurance status in countries, such as the US [26], where private health insurance is required, has been shown to influence readmission rates, this factor has no impact on the UK population since all aspects of emergency care are covered by the NHS.

Using two-graph ROC analysis, we have demonstrated that the thresholds of the LACE index to identify mortality and frequent admissions vary widely with age. Thus, the use of a single LACE index threshold at 10 to define high risk is not applicable for all ages, particularly for the less-studied younger individuals. It is important to emphasise that the two-graph ROC analysis (Fig. 2) is employed to facilitate objective decisions on desired LACE index thresholds.
When a desired LACE index threshold is selected, a number of factors should then be taken into account, including clinical benefits and risks, costs of interventions and physiological characteristics (such as age) of the individual [27]. Since the value for $\theta_{0}$ was below a preselected accuracy level (95\%), two cut-off values representing the upper and lower limits of $\mathrm{IR}_{95 \%}$ were considered as the borderline range for the clinical interpretation of test results [23] if high sensitivity is desired, the LACE index threshold is lowered towards the lower limit of $\mathrm{IR}_{95 \%}$ but specificity is compromised. Conversely, raising the LACE index threshold towards the upper limit of $\mathrm{IR}_{95 \%}$ would reverse these conclusions. The IR can also be varied, e.g. by lowering the points where sensitivity and specificity equal $90 \%\left(\mathrm{IR}_{90 \%}\right)$, which would result in a narrower IR [28].

Likelihood ratios are useful statistics for measuring the accuracy of a diagnostic test in clinical practice [29]. They have a number of advantages over sensitivity and specificity or predictive values: they can capture the size of abnormality of test results, are independent of disease prevalence, therefore, are more stable than predictive values when prevalences vary, and they can be used at the individual patient level [30]. Report of likelihood ratios is, therefore, recommended for inclusion in clinical studies. The likelihood ratio is derived from the ratio of the probability of a given test result in patients with poor outcome (i.e. mortality or frequent readmissions) to the probability of the same test result in patients without poor outcome. The further likelihood ratios are from unity, the stronger the evidence for the presence or absence of adverse outcome: $L R+$ over 10 and LR- less than 0.1 indicate strong evidence to confirm or exclude the diagnosis of interest, respectively [31]. We observed that the likelihood ratios for predicting mortality (LR+range: 1.5-3.3 and LR - range: 0.4-0.6) and frequent readmissions after hospital discharge (LR+ range: 2.5-4.4 and LR - range: $0.3-0.6$ ) were relatively modest, but generally the evidence was stronger in younger than in older individuals.

Findings from this study indicate that interventional plans to reduce frequent readmissions should be directed at younger individuals who have the greatest probability of future readmissions. There is a misconception that to reduce readmissions, it is necessary to focus targeted interventions at "high-risk" groups, such as the very ill or very old (over 80 years), who actually account for a relatively small share of a total number of admissions (27\% in this study). It has been argued that because the majority of admissions are from low-risk individuals, significant risk reduction can only be achieved if interventions to reduce risk factors were applied to the whole population [32]. An effort to reduce readmissions of older people, while neglecting younger individuals, may also suffer from the regression to the mean effect [33]. This phenomenon was well demonstrated in a study by 
Roland et al. [18] It was observed that patients $\geq 65$ years with $\geq 2$ admissions were responsible for $38 \%$ of admissions in the index years. However, without any intervention this reduced to about $10 \%$ in the following years and further to $3 \%$ of admissions 5 years later. This is likely to be due to high mortality rates among older individuals-data in this study showed that up nearly $20 \%$ of individuals over 70 years who were admitted $\geq 2$ times within 28 days of hospital discharge died within 6 months compared with $<5 \%$ among those younger than 60 years. Thus, by lowering the "high-risk" LACE index score to our derived threshold values of as low as 5 for younger individuals would encompass the majority of those who account for most admissions in the long term. We found that less than $20 \%$ of the youngest group who died within 6 months of hospital discharge were identified by a LACE index threshold of $>10$, whilst up to $80 \%$ were identified when the threshold was lowered to 5 . More patients were also identified by age-specific thresholds up to 69 years. These findings were further reinforced by similar results from age-specific LACE index thresholds in the prediction of frequent readmissions.

If the LACE index threshold was raised from 10 to 11.5 for the oldest group, then the total numbers would be smaller but have a greater proportional mortality rate, i.e. there would be fewer false negatives while missing some with a score of 10 who will die, but not be picked up by this stratification. On the other hand, by staying at 10 , more false positives are introduced and some true positives will be missed. Thus, the balance between resources and optimising recognition of risk should be taken into account when selecting a threshold. We found that those with a LACE score $\geq 10,1127$ deaths were identified. When the threshold was increased to 11.5 , there were 867 deaths with a score above this threshold (a reduction of $23.1 \%$ ).

The strengths of this study lie in its large number of patients which enable us to derive age-specific thresholds of LACE index in the identification of mortality in a wide range of age (18 to 107 years). We define frequent readmissions for those who were admitted $\geq 2$ times within 28 days. Certain limitations may arise from patients who have left our catchment area, particularly younger age groups who may find new jobs or have other social commitments-this would inevitably alter readmission rates. Although the accuracy of the test is a fair parameter for describing the diagnostic performance of the test itself, it doesn't necessarily influence clinical decision-making. The validation of pre-specified sensitivity and specificity of LACE index thresholds could be more useful if a clinical strategy could be followed after the application of the test to establish whether reductions in mortality and frequent readmissions could be achieved.

In conclusion, the LACE index predicts mortality and frequent readmissions with greater accuracy and at lower thresholds in younger compared to older individuals. Age should be taken into account when using the LACE index for identifying patients at high risk. However, clinical usefulness of this index still depends on the validation of specific thresholds and on the definition of a specific strategy for mortality and frequent hospital readmissions.

Acknowledgements The authors wish to thank patients and all those who were involved in the surveys.

Author contributions TSH reviewed the topic related literature and performed the study concept and analysis design. EH performed the study coordination and data collection. TSH wrote the first draft, analysed, interpreted the data and revised the manuscript. CHF and DF edited the manuscript. All authors checked, interpreted results and approved the final version.

\section{Compliance with ethical standards}

Conflict of interest The authors declare that they have no conflicts of interest.

Ethical approval This study does not require NHS Research Ethics Committee approval since it involves secondary analysis of anonymised data. This study was conducted in accordance with the 1964 Helsinki declaration and its later amendments or comparable ethical standards.

Statement of human and animal rights This article does not contain any studies with animals performed by any of the authors.

Informed consent Informed consent was obtained from all individual participants included in the study.

Open Access This article is licensed under a Creative Commons Attribution 4.0 International License, which permits use, sharing, adaptation, distribution and reproduction in any medium or format, as long as you give appropriate credit to the original author(s) and the source, provide a link to the Creative Commons licence, and indicate if changes were made. The images or other third party material in this article are included in the article's Creative Commons licence, unless indicated otherwise in a credit line to the material. If material is not included in the article's Creative Commons licence and your intended use is not permitted by statutory regulation or exceeds the permitted use, you will need to obtain permission directly from the copyright holder. To view a copy of this licence, visit http://creativecommons.org/licenses/by/4.0/.

\section{References}

1. https://files.digital.nhs.uk/63/C61B23/HESF\%20Monthly\%20Rep ort $\% 20$ NHSdigital.pdf. Accessed 15 Apr 2020

2. https://digital.nhs.uk/data-and-information/publications/clinicalindicators/nhs-outcomes-framework/archive/nhs-outcomes-frame work-indicators-february-2019-release. Accessed 15 Apr 2020

3. Barrett ML, Wier LM, Jiang HJ, Steiner CA (2015) All-cause readmissions by payer and age, 2009-2013. HCUP Statistical Brief\# 199. Agency for Healthcare Research and Quality, Rockville

4. Mayr FB, Talisa VB, Balakumar V, Chang CC, Fine M, Yende S (2017) Proportion and cost of unplanned 30-day readmissions after sepsis compared with other medical conditions. JAMA 317:530-531 
5. Nolte E, Roland M, Guthrie S, Brereton L (2012) Preventing emergency readmissions to hospital: a scoping review. Rand Health Q 2:10

6. Mcllvennan CK, Eapen ZJ, Allen LA (2015) Hospital readmissions reduction program. Circulation 131:1796-1803

7. Wallace E, Smith SM, Fahey T, Roland M (2016) Reducing emergency admissions through community based interventions. BMJ 352:h6817

8. Steventon A, Billings J (2017) Preventing hospital readmissions: the importance of considering 'impactibility', not just predicted risk. BMJ Qual Saf 26:782-785

9. Frost DW, Vembu S, Wang J, Tu K, Morris Q, Abrams HB (2017) Using the electronic medical record to identify patients at high risk for frequent emergency department visits and high system costs. Am J Med 130(5):601-e17

10. van Walraven C, Dhalla IA, Bell C, Etchells E, Stiell IG, Zarnke K, Austin PC, Forster AJ (2010) Derivation and validation of an index to predict early death or unplanned readmission after discharge from hospital to the community. CMAJ 182:551-557

11. Cotter PE, Bhalla VK, Wallis SJ, Biram RW (2012) Predicting readmissions: poor performance of the LACE index in an older UK population. Age Ageing 41:784-789

12. Amarasingham R, Velasco F, Xie B, Clark C, Ma Y, Zhang S, Bhat D, Lucena B, Huesch M, Halm EA (2015) Electronic medical record-based multicondition models to predict the risk of 30 day readmission or death among adult medicine patients: validation and comparison to existing models. BMC Med Inform Decis Mak 15:39

13. Shaffer BK, Cui Y, Wanderer JP (2019) Validation of the LACE readmission and mortality prediction model in a large surgical cohort: comparison of performance at preoperative assessment and discharge time points. J Clin Anesth 58:22-26

14. Tan SY, Low LL, Yang Y, Lee KH (2013) Applicability of a previously validated readmission predictive index in medical patients in Singapore: a retrospective study. BMC Health Serv Res 13:366

15. Fonseca J, Costa F, Mateus J, Ferreira D, Clemente H, Veríssimo M, Caravalho A (2017) Identification of high-risk patients for early death or unplanned readmission using the LACE index in an older Portuguese population. F1000Research 6(1798): 1798

16. Gruneir A, Dhalla IA, van Walraven C, Fischer HD, Camacho X, Rochon PA, Anderson GM (2011) Unplanned readmissions after hospital discharge among patients identified as being at high risk for readmission using a validated predictive algorithm. Open Med 5:e104-e111

17. Wang H, Robinson RD, Johnson C, Zenarosa NR, Jayswal RD, Keithley J, Delaney KA (2014) Using the LACE index to predict hospital readmissions in congestive heart failure patients. BMC Cardiovasc Disord 14:97

18. Roland M, Dusheiko M, Gravelle H, Parker S (2005) Follow up of people aged 65 and over with a history of emergency admissions: analysis of routine admission data. BMJ 330:289-292
19. Heppleston E, Fry CH, Kelly K, Shepherd B, Wright R, Jones G, Robin J, Murray P, Fluck D, Han TS (2020) LACE index predicts age-specific unplanned readmissions and mortality after hospital discharge. Aging Clin Exp Res. https://doi.org/10.1007/s4052 0-020-01609-w (Online ahead of print)

20. Schneeweiss S, Wang PS, Avorn J, Glynn RJ (2003) Improved comorbidity adjustment for predicting mortality in Medicare populations. Health Serv Res 38:1103-1120

21. Romano PS, Roos LL, Jollis JG (1993) Adapting a clinical comorbidity index for use with ICD-9-CM administrative data: differing perspectives. J Clin Epidemiol 46:1075-1079

22. www.mdcalc.com/lace-index-readmission. Accessed 15 Apr 2020

23. Greiner M, Sohr D, Göbel P (1995) A modified ROC analysis for the selection of cut-off values and the definition of intermediate results of serodiagnostic tests. J Immunol Methods 185:123-132

24. Han TS, Van Leer EM, Seidell JC, Lean ME (1996) Waist circumference as a screening tool for cardiovascular risk factors: evaluation of receiver operating characteristics (ROC). Obes Res 4:533-547

25. Han TS, Gulli G, Affley B, Fluck D, Fry CH, Barrett C, Kakar P, Sharma S, Sharma P (2019) New evidence-based A1, A2, A3 alarm time zones for transferring thrombolysed patients to hyperacute stroke units: faster is better. Neurol Sci 40:1659-1665

26. Sox CM, Burstin HR, Edwards RA, O'Neil AC, Brennan TA (1998) Hospital admissions through the emergency department: does insurance status matter? Am J Med 105:506-512

27. Zou KH, O’Malley AJ, Mauri L (2007) Receiver-operating characteristic analysis for evaluating diagnostic tests and predictive models. Circulation 115:654-657

28. Lisk R, Yeong K, Fluck D, Fry CH, Han TS (2020) The ability of the Nottingham Hip Fracture Score to predict mobility, length of stay and mortality in hospital, and discharge destination in patients admitted with a hip fracture. Calcif Tissue Int. https:// doi.org/10.1007/s00223-020-00722-2 (Online ahead of print)

29. Zandbergen EG, de Haan RJ, Stoutenbeek CP, Koelman JH, Hijdra A (1998) Systematic review of early prediction of poor outcome in anoxic-ischaemic coma. Lancet 352:1808-1812

30. Deeks JJ, Altman DG (2004) Diagnostic tests 4: likelihood ratios. BMJ 329:168-169

31. Grimes DA, Schulz KF (2005) Refining clinical diagnosis with likelihood ratios. Lancet 365:1500-1505

32. Rose G (1985) Sick individuals and sick populations. Int J Epidemiol 14:32-38

33. Roland M, Abel G (2012) Reducing emergency admissions: are we on the right track? BMJ 345:e6017

Publisher's Note Springer Nature remains neutral with regard to jurisdictional claims in published maps and institutional affiliations. 